\title{
Docência na universidade: a auto-eco-formação como possibilidade de reprofissionalização
}

\section{Docencia en la universidad: la auto-eco-formación como posibilidad de reprocesión}

\author{
Teaching at university: self-eco-training as a possibility of \\ reprofessionalization
}

\author{
Daniele Simões Borges ${ }^{1}$ \\ Veronica Cunha Barcellos ${ }^{2}$
}

\begin{abstract}
Resumo
Este artigo apresenta parte de uma pesquisa teórica reflexiva que tem como proposta desenvolver reflexões sobre a auto-eco-formação enquanto uma possibilidade de reprofissionalização do professor atuante no ensino superior. Diante disso, hodiernamente, entre os principais desafios para a melhoria da Educação Superior no Brasil, está a necessidade de formação pedagógica dos professores universitários. Trata-se do fortalecimento da especificidade da docência enquanto uma profissão que agrega as especialidades, mas, sobretudo desenvolve-se por meio da articulação entre a gestão, a pesquisa, o ensino e a extensão. Desse modo, não podemos deixar a dimensão pedagógica da docência universitária apenas na perspectiva do ensino. Acreditamos e defendemos que é na integração - complementar e integrada- da tétrade gestão-ensino-extensão-pesquisa por meio da auto-ecoformação que a ação docente poderá ser pensada em novas bases fazendo avançar, coletivamente, na construção do conhecimento acerca do ser professor no ensino superior. Por fim, a pesquisa tem como orientador o pensamento complexo, detidamente nos estudos de Edgar Morin, procurando as aproximações entre a complexidade, a auto-formação e a eco-formação.
\end{abstract}

Palavras-Chave: Auto-formação; eco-formação; docência universitária.

\section{Resumen}

Este artículo presenta parte de una investigación teórica reflexiva que tiene como propuesta desarrollar reflexiones sobre la auto-eco-formación como una posibilidad de reprofisionalización del profesor actuante en la enseñanza superior. Frente a ello, entre los principales desafíos para la mejora de la Educación Superior en Brasil, está la necesidad de formación pedagógica de los profesores universitarios. Se trata del fortalecimiento de la especificidad de la docencia como una profesión que agrega las especialidades, pero sobre todo se desarrolla por medio de la articulación entre la gestión, la investigación, la enseñanza y la extensión. De este modo, no podemos dejar la dimensión pedagógica de la docencia universitaria sólo en la perspectiva de la enseñanza. Creemos y defendemos que es en la integración-complementaria e integrada- de la tétrica gestión-enseñanzaextensión-investigación por medio de la auto-eco-formación que la acción docente podrá ser pensada en nuevas bases haciendo avanzar colectivamente en la construcción del conocimiento acerca del tema, ser profesor en la enseñanza superior. Por último, la investigación tiene como orientador el pensamiento complejo, detenidamente en los estudios de Edgar Morin, buscando las aproximaciones entre la complejidad, la auto-formación y la ecoformación.

Palabras claves: Autoformación; eco-formación; docencia universitaria.

\begin{abstract}
This article presents part of a reflexive theoretical research whose purpose is to develop reflections on self-ecotraining as a possibility of reprofessionalization of the teacher acting in higher education. Among the main challenges for the improvement of Higher Education in Brazil is the need for pedagogical training of university

\footnotetext{
${ }^{1}$ Doutora em Educação em Ciências; Universidade Federal do Rio Grande - FURG; Rio Grande, Rio Grande do Sul e Brasil; daniele.uab@ gmail.com

${ }^{2}$ Mestranda em Educação; Universidade Federal do Rio Grande - FURG; Rio Grande, Rio Grande do Sul e Brasil; veronicacunhabarcellos@gmail.com
} 
teachers. It is about strengthening the specificity of teaching as a profession that adds to the specialties, but it mainly develops through the articulation between management, research, teaching and extension. We can not leave the pedagogical dimension of university teaching only in the perspective of teaching. We argue that it is in the integration - complementary and integrated - of the management-teaching-extension-research-tetrad through self-eco-training that the teaching action can be thought of in new bases, advancing collectively in the construction of knowledge about being a teacher in higher education. The research has as a guide the complex thinking, closely in the studies of Edgar Morin, looking for the approximations between the complexity, the selfformation and the eco-formation.

Keywords: Self-training; eco-training; university teaching..

\section{Introdução}

Quando pensamos na carreira do professor universitário vislumbramos um itinerário de trabalho diverso, com desdobramentos que vão desde a formação profissional aos graduandos; a produção de capital intelectual; a atuação na pós-graduação; a interação com as comunidades vias atividades extensionistas e, ainda, a gestão, que se estende desde o trabalho de gestão do seu grupo de pesquisa como também de atuação em cargos ou funções que envolvem uma carga horária significativa em atividades de cunho burocrática. Aliás, a gestão cada vez mais vem se colocando enquanto uma dimensão chave no trabalho docente do magistério superior (BORGES, 2018).

Todas as atividades supracitadas passam a ser excetuadas, muitas vezes, sem uma formação ou orientação que atenda as especificidades da ação a ser desempenhada. Essa situação nos faz pensar sobre uma vertente ainda presente no discurso pedagógico oficial que é a baseada na racionalidade técnica. Para sanar os efeitos da diversidade do trabalho docente dentro de uma instituição universitária agrega-se ao professor também um papel executor.

Por isso, concordamos com que a formação docente é um processo contínuo. O professor não é o executor, mas deverá ser o autor da sua intervenção profissional. Todas as atividades vinculadas ao trabalho docente do professor auxiliam na manutenção das ações de uma comunidade universitária. Logo, aos docentes que ali atuam cabe apropriar-se dessas dimensões para inclui-las em sua agenda de trabalho. Com isso, queremos dizer que o professor universitário produz aulas, mas também realiza inúmeras atividades que vem caracterizando essa profissão para além da sala de aula.

Nesse sentido, a profissionalização para a docência na Educação Superior é uma importante perspectiva que não pode ser desconsiderada. Desse modo, neste artigo temos como objetivo tecer reflexões sobre a auto-eco-formação enquanto uma possibilidade de reprofissionalização do professor atuante no ensino superior. Buscamos respaldo na premissa de que a docência universitária se desenvolve por meio de um processo de reprofissionalização continuada. Ou seja, entrelaçando saberes da formação inicial, num 
processo de construção profissional sobre a docência, contextualizado e historicamente situado.

Cunha (2010) nos explica que um caminho para se pensar na formação do professor universitário pode ser o de problematizar a profissionalidade. Marcelo Garcia (2001), também corrobora com esse entendimento, porém ele vem escrevendo sobre o desenvolvimento profissional (profissionalidade) a fim de indicar a construção profissional perdura ao longo da vida e da atuação do professor, integrando a dimensão da pessoal e profissional.

Para Cunha (2010), o termo de profissionalidade agrega-se ao termo de profissionalização, contudo ele avança. Esse conceito vem assumindo a docência como um campo de inúmeras interações, humanas, políticas, sociais e culturais, que o fazem um lugar de metamorfose constante. Logo, profissionalidade traz "[...] a ideia de ser a profissão em ação, em processo, em movimento" (CUNHA, 2010, p. 31). Podemos dizer que o termo profissionalização vincula-se facilmente como uma etapa constituinte da formação inicial, está ligado a construção técnica a respeito da atividade que será desenvolvida (ROLDÃO, 2008). Contudo, o exercício da docente não se contempla apenas de uma dimensão técnica.

Quando pensamos na carreira do professor universitário e nas suas atividades comumente ouvimos se falar que se é professor o mesmo deverá "dar aulas", mas o processo de ensinar não se limite apenas nisso. Em outras palavras, há um conjunto de saberes próprios que definem nossa profissão, temos sim que desenvolver práticas educativas, porém, o contexto da ação docente não se reduz a uma sala de aula. Somos interpelados por diversas interações que interligadas às ações, as reflexões e as produções geridas no cotidiano dessa profissão que nos mostram que a docência se caracteriza pela ação mediadora e dialógica na construção de conhecimentos variados. São pensamentos, saberes e discursos que vem sustentando o valor pedagógico dessa profissão. Mas, é importante ponderar que esses saberes “[...] não são conhecimentos empíricos que se esgotam no espaço da prática, no chamado “aprender fazendo"” (CUNHA, 2010, p. 23). Segundo Tardif (2002) os saberes docentes podem ser compreendidos saberes da formação profissional, os saberes disciplinares, curriculares e experienciais. Os mesmos articulam-se e estão integrados ao processo de desenvolvimento profissional sendo impossível coloca-los em polos. Desse modo, salientamos a importância de uma reflexão conceitual acerca desses diferentes saberes que compõem a docência universitária e que ao mesmo tempo anunciam a sua complexidade.

Entendemos que diante dessa complexidade e da atuação do professor universitário em relação suas atividades no ensino, na pesquisa, na extensão e na gestão o mesmo vem se produzindo por meio de um processo de auto-ecoformação. Desse modo, quando acolhemos a 
perspectiva de desenvolvimento profissional indicamos que ser professor instiga a tarefa de auto-ecoprodução e aperfeiçoamento permanentemente na e pelas interações coproduzidas em sua atuação. São os produtos dessa rede de dialógica nutrida de interações materiais, entre pessoas, subjetivas e intersubjetivas que contribuem e levam ao aprimoramento de seu trabalho e de sua pessoa ao longo da sua vida.

\section{Professor na Educação Superior}

Ser professor universitário é assumir o desafio de compreender a docência para além da sala de aula, mas fazendo-a estabelecendo relações educativas visando desenvolver competências necessárias ao bom exercício da sua profissão. Educar os jovens e os adultos que frequentam o ensino superior não é uma tarefa simples, posto que além dos saberes disciplinares e específicos para se formar um profissional, quando pensamos numa formação universitária, não podemos perder de vista o desejo em “[...] propiciando-lhes um desenvolvimento humano, cultural, científico e tecnológico, de modo que adquiram condições para enfrentar as exigências do mundo contemporâneo" (PIMENTA e ANASTASIOU, 2010, p. 13).

A lógica do recrutamento dos professores para atuação na Educação Superior não legitima o conhecimento pedagógico ou a valorização da ação educativa. Os processos seletivos são estabelecidos por meio de provas, na maioria das vezes, escrita, didática, entrevista/defesa de memorial e análise do currículo. Assim, a docência aparece como uma segunda profissão, pois a primeira se localiza principalmente na formação inicial ou ainda como uma aptidão, algo que não carece de estudo específico. Ou seja, encontramos o médico, o biólogo, o advogado, o escritor, mas os mesmos, em alguns casos, poucos compreendem sobre o saber pedagógico necessário para atuação nesse campo profissional.

Esse cenário nos exemplifica os quantos ainda precisaremos buscar pela valorização dos conhecimentos pedagógicos para atuação do docente na Educação Superior. Diante disso, autores como Almeida (2012), Anastasiou (2011) e Cunha (2010) afirmam que os processos de profissionalização continuada e formação pedagógica necessitam ser problematizados de todos os níveis, mas, principalmente o universitário. Para as autoras supracitadas, já é consenso que as instituições de Educação Superior carecem desenvolver e investir em programas e/ou estratégias de formação e de acompanhamento profissional ao seu corpo docente. De acordo com Almeida (2012, p. 34) “o estabelecimento de políticas institucionais destinadas a pôr em prática projetos de formação docente com caráter permanente representa 
uma mudança de paradigma no desenvolvimento das políticas das instituições de ensino superior".

Zabalza (2004) explica que o trabalho docente se construiu por meio de três funções: a) o ensino, b) a pesquisa e c) a administração desenvolvidos nos variados setores da instituição. Desse modo, os processos que dinamizam a docência na Educação Superior cumprem atividades, muito embora não sejam desenvolvidas harmoniosamente, estas carregam significados complexos relacionados com as questões culturais, pessoais, políticas, éticas, epistêmicas e educativas. Assim, a docência "é muito maior" e "[..] a atuação dos professores precisa necessariamente resultar da convergência e articulação equilibrada entre as dimensões científica, investigativa e pedagógica” (ALMEIDA e PIMENTA, 2011, p. 24).

Não é possível fazer uma leitura das partes sem pensar nos laços e nas interações que produzem 'o todo' do trabalho do professor. Ao mesmo tempo, a frágil compreensão da missão educativa da universidade, já identificada na literatura da área, nos mostra que diante das limitações com relação ao ensino- enraizada via um percurso formativo cultivado pelo conservadorismo-, precisamos reestabelecer, conforme exprime Morin (2008), ao que é tecido junto- complexus da profissão-, para assim seguir na busca de caminhos viáveis para reorganizar a imagem pessoal, o desempenho e os elementos motivacionais que levam esses sujeitos à docência.

Nessa perspectiva, acreditamos que precisamos criar alternativas diante do desprestígio da docência no contexto da Educação Superior. Porém, a intenção principal é destacar que no meio dessas escolhas para recuperar a importância da pedagogia no âmbito da carreira universitária os estudos de Borges (2018) apontaram que os professores universitários compreendem a docência universitária sem orientação com relação a sua tarefa educativa. E, diante dos desafios iminentes a prática educativa os mesmos vem buscando alternativas formativas para respaldarem suas atividades didáticas pedagógicas. Contudo, o que preocupa é que o seio de tais processos formativos não é propiciado pelas instituições, mas localizados numa perspectiva auto-formativa, que acarreta ainda mais na solidão do professor universitário.

\section{A auto-eco formação enquanto possibilidade de reprofissionalização}

Não podemos negar que a ampliação das funções docentes nos mostra que suas ações superam a sala de aula. A prática profissional do professor universitário tem se diversificado em múltiplas funções e atividades. Entendemos que na universidade a prática docente 
necessita articular o ensino com a pesquisa, a pesquisa com a gestão, a gestão com a extensão e assim recursivamente.

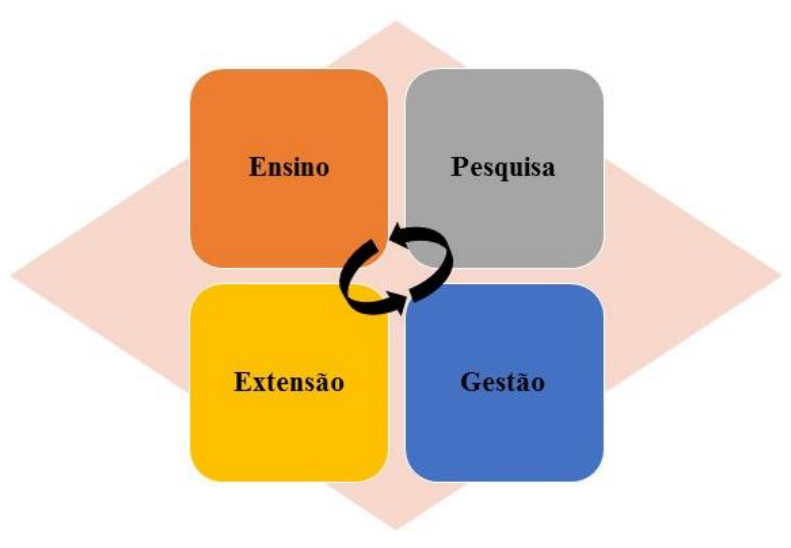

Figura 1: Campos de ação da docência universitária

Ambos os campos de ação vão dando condições de estabelecer a formação crítica e integral, que nada mais é do retorno social que a sociedade espera da universidade. Nesse contexto, a docência vem nutrindo-se dessas ações, porém o prestigio dado ao magistério superior não vem da atuação integrada nesses campos e sim é mais preponderante aquele que tem destaque na pesquisa, aderindo maior valorização ao professor que domina as ferramentas investigativas (CUNHA, 2010).

Corroboramos ainda que a pesquisa amplia os horizontes dos sujeitos envolvidos e estende-se aos outros com seus resultados. O ensino, por sua vez, mobiliza as inquietações dos professores e alunos, propiciando novos sentidos às interpretações ressignificando a própria pesquisa. A extensão fornece as possibilidades de interação com a sociedade, com a Educação Básica, com os problemas sociais, com os saberes populares é a possibilidade de ressignificação da prática com a teoria. A gestão, por sua vez, garante a possibilidade de tomada de decisões, é o espaço para implementar mudanças que visam ou pelo menos deveriam primar para além da responsabilização individual, mas num campo de ação no qual o trabalho de raiz burocrática seja acompanhado de bases teóricas, reflexivas e críticas que possibilitem compreender o papel social, formativa e institucional da vida universitária.

No entanto, como equilibrar essas variadas tarefas da docência tendo como precedente a insuficiência do ponto de vista formativo da universidade para/com seus docentes? 
Kourganoff (1990) defende que as tradições da organização da carreira universitária impactaram o modo de enxergar o professor universitário: o prestígio advém do domínio do conhecimento, de um especialista e no que ele produz sobre sua especialidade. É incipiente a valorização da pedagogia universitária ou da íntima inter-relação entre a dimensão científica e a dimensão pedagógica no cotidiano acadêmico. Dadas às condições históricas e culturais, é necessário compreender que "a carreira universitária se estabelece na perspectiva de que a formação do professor requer esforços apenas na dimensão científica do docente, materializada pela pós-graduação" (CUNHA, 2009, p. 85).

Almeida e Pimenta (2011) afirmam que dentre os professores universitários não são raros os casos de desconhecimento acerca dos processos de ensinar e aprender na universidade. De fato, como já salientamos, o professor universitário que não teve nenhuma formação inicial pedagógica vem se construindo professor baseado principalmente em suas memórias escolares e por tentativas, por momentos acertando e por outros se equivocando.

Nas palavras de Almeida e Pimenta (2011), a universidade é uma instituição educativa que se sustenta e evolui através da produção do conhecimento na pesquisa, no ensino e na extensão. Portanto, para que continue com sua missão é necessário que se produzam mudanças com relação à valorização dos diferentes campos de ação no trabalho docente. São transformações necessárias para concretização de uma nova cultura acadêmica que estime o trabalho dos docentes e dê visibilidade para as práticas de ensino, de pesquisa, de extensão e de gestão.

Para Nóvoa (1994), a inexistência de um trabalho coletivo de socialização profissional acarreta no favorecimento de posturas pedagogicamente carentes e/ou equivocadas por parte dos docentes. Ou seja, a instituição tem um papel importante no sentido de proporcionar um trabalho coletivo e as ações formativas para uma socialização profissional, diminuindo, assim, do professor iniciante, o desconforto face as suas incompreensões com relação a sua própria atividade docente.

Desse modo, defendemos a compreensão da necessária articulação entre auto e eco formação para as políticas institucionais bem como para as políticas públicas nacionais para formação e valorização do professor. O que queremos dizer é que é recorrente na carreira do professor a experiência auto-formativa numa perspectiva individual e solitária, muitas vezes. O processo de reflexão, os planejamentos das atividades educativas, a participação em congressos, a escrita quando estão dispostas apenas no plano do Eu munidas de um discurso de autonomia vem se desenvolvendo como principal vetor de formação continuada dos professores universitários. 
Para Borges (2018) inspirada nos estudos da complexidade à dimensão auto no processo de desenvolvimento profissional tem se destacado pela maior recorrência nos percursos de formação continuada realizado pelos professores. Essa dimensão está diretamente imbricada pela tomada de consciência, relação autonomia e dependência entre o que eu consigo resolver e que eu preciso aperfeiçoar. Contudo, numa análise pormenorizada, a auto-formação sozinha sobrecarrega ainda mais o trabalho docente uma vez que se vincula à individualidade. Nesse sentido entra dimensão eco, que potencializa a interação entre auto (ser) e eco (ser no contexto e com as pessoas). (BORGES, 2018).

Porém, não é simples estabelecer a retroação entre auto e eco no processo de formação. Primeiro que esse é um movimento que precisa de elementos motrizes. Não podemos negar que há tendências políticas que sugestionam o modo de como os professores se desenvolvem. A título de exemplo, toda orientação metodológica está impregnada de uma identificação epistemológica e esta, por sua vez, é dependente de um sistema de ensino regido por meio de políticas públicas. Quer dizer que não existe autonomia total, a identidade docente vai sendo construída ao longo das suas interações e são elas que também influenciam a ação educacional, tanto da esfera macro (políticas) como no micro (pessoas).

Por essa razão, não basta apenas argumentar que deve ser feito a integração entre o auto e eco formação, isso demostra apenas o diagnóstico. O que defendemos é que precisamos de engajamento institucional para que efetivamente seja realizado um corpo formativo que preze tantos os aspectos particulares vinculados, muitas vezes, nas características peculiares à área de atuação e a fase da fase em que se encontra do seu processo de desenvolvimento profissional. De modo geral, na universidade encontramos professores iniciantes, experiências e estabelecidos. Ambos apresentam questões diferentes para sua formação. $O$ modelo tradicional de formação para professores universitários, que se dá por meio de palestras ou temas em grande parte não percebe essas singularidades, pois são propostas generalistas.

Desse modo, as formações propostas pela instituição que não levam em conta essas tênues diferentes entre os grupos dos docentes. No que concerne ao desenvolvimento profissional, essas ações que querem homogeneizar a identidade docente acabam por contribuir para um processo de desvalorização da identidade profissional (SACRISTÁN, 1999).

Nessa perspectiva, inserimos a ideia de reprofissionalização da docência. Isso quer dizer, de acordo com os estudos de Marcelo Garcia (2001), a atividade docente vem passando por um processo contínuo de reprofissionalização uma vez que seus campos de ação foram ampliados. É como defendemos anteriormente, ao professor já não basta mais ensinar, ele ao 
ensinar contemporaneamente igualmente faz pesquisa, produz novos saberes, administra processos de gestão, coordena intervenções e produções sociais, culturais e políticas. Sacristán (1999) argumenta que essa diversificação e intensificação do trabalho docente vêm contribuindo para um processo de desprofissionalização. Preferimos não aderir esse ponto de visto aos nossos estudos, uma vez que concordamos com o referido autor que algumas condições, de maneira geral, as predefinidas exteriormente aos docentes, por exemplos, avalições externas, políticas de regulação da docência, discursos que colocam a profissão docente enquanto um ligar comum, na qual basta um "saber notório" que poderás ensinar alguma coisa a alguém, evidenciam um canal de ataque à profissão. Entretanto, com relação à ampliação das funções do professor, aderimos um olhar positivo, que diz respeito a diversidade ações que não limitam-se mais a sala de aula, mas que fazem dessa profissão com campo frutuoso de experiências que não estagnam com o passar do tempo.

Assim, a reprofissionalização diz respeito às alterações hodiernas no trabalho do professor, e quando pensamos no magistério superior essas funções foram especialmente estendidas nas últimas três décadas. Isso nos coloca a necessidade de integração auto e eco, pois a ação educativa precisa de diálogo, de organização em equipe, tomadas de decisões cooperativas, do planejamento estratégico, da formação contínua pela prática profissional (MARCELO GARCIA, 2001).

\section{Considerações Finais}

Esse artigo buscou compreender auto-eco-formação enquanto uma possibilidade que dará suporte para a reprofissionalização do professor universitário. Desse modo, fomos defendendo nosso ponto de vista buscando ampliar as compreensões sobre o desenvolvimento profissional e as particularidades da carreira do professor no ensino superior. Sendo assim, observou-se que no contexto atual a formação contínua dos professores universitários ainda está arraigada a uma ideia tradicional de matriz não heterogenia que incipientemente vem se mostrando presente em propostas institucionais generalistas e abrangentes. Logo, para dar conta dos desafios os professores estão, por si, buscando possibilidades de aperfeiçoamento. Diante disso, a dimensão auto-formativa é protagonista nas práticas e ações de desenvolvimento profissional.

Contudo, acreditamos que é papel institucional promover maiores possibilidades de integração entre o auto e o eco para assim dar condições efetivas para os professores constituírem uma postura reflexiva diante do contexto em que atuam. Nós, pesquisadores da 
Educação Superior, já temos o diagnóstico das propostas de formação que de maneira tradicional levaram ao esgotamento e a desvalorização dos processos de formação continuada. Já temos, entretanto, alguns caminhos que numa leitura mais transdisciplinar já identificam e reconhecem a auto-formação na vida do professor. Essa constatação pode ser crucial para repensar os modelos dos cursos e propostas de formação continuada. Preciso integrar o professor, pensante e sujeito de si, a um processo maior, promovendo um fortalecimento da pedagogia universitária por meio de práticas cooperativas, colaborativas e de intercâmbio de saberes e experiências.

\section{Referências}

ALMEIDA, Maria Isabel de. Formação do professor do ensino superior: desafios e políticas institucionais. São Paulo: Cortez, 2012.

ALMEIDA, Maria Isabel de; PIMENTA, Selma Garrido. A construção da pedagogia universitária no âmbito da Universidade de São Paulo. In.: PIMENTA; Selma Garrido; ALMEIDA, Maria Isabel de. (Org.). Pedagogia universitária: caminhos para a formação de professores. São Paulo: Cortez, 2011. p. 19-43.

ANASTASIOU, Léa das Graças Camargos. Processos formativos de docentes: aspectos teóricos e práticos. In.: PIMENTA; Selma Garrido; ALMEIDA, Maria Isabel de. (Org.). Pedagogia universitária: caminhos para a formação de professores. São Paulo: Cortez, 2011. p. 44-74.

BORGES. Daniele Simões. Docência iniciante na universidade: interações auto-ecoorganizadoras da formação. 162f. Tese (Doutorado), Programa de Pós-Graduação em Educação em Ciências. Universidade Federal do Rio Grande - FURG. Rio Grande, 2018. Disponível em: https://argo.furg.br/?BDTD11825. Acesso em: 5 ago. 2018.

CUNHA, Maria Isabel da. A docência como ação complexa. In: CUNHA, Maria Isabel da (Org.). Trajetórias e lugares de Formação da docência universitária: da perspectiva individual ao espaço institucional. Araraquara, São Paulo: Junqueria\&Marin, 2010. p.19-34.

CUNHA, Maria Isabel da. O lugar da formação do professor universitário: o espaço da pósgraduação em educação em questão. Rev. Diálogo Educ., Curitiba, v. 9, n. 26, p. 81-90, 2009.

KOURGANOFF, Wladimir. A face oculta da universidade. Trad. Cláudia Schilling e Fátima Murad. São Paulo: Editora da Universidade Estadual Paulista, 1990.

MARCELO GARCÍA, Carlos La función docente: nuevas demandas en tiempos de cambio. In: MARCELO GARCÍA, Carlos. (Org.). La función docente. Madrid: Editorial Síntesis, 2001. p. 9-26.

MORIN, Edgar. Método I: a natureza da natureza. Trad. Juremir Machado da Silva. $2^{\mathrm{a}}$ ed. Porto Alegre: Sulina, 2008. 
NÓVOA, António (Org.). Vida de professores. Porto: Porto Editora, 1994.

PIMENTA, Selma Garrido; ANASTASIOU, Léa das Graças Camargo. Docência no Ensino Superior. 4 ed. São Paulo: Cortez, 2010.

ROLDÃO, Maria do Céu. Profissionalidade docente em análise: especificidades dos ensinos superior e não superior. Nuances: Estudos Sobre Educação, ano XI, v. 12, n. 13, p. 105-126, jan./dez. 2005.

SACRISTÁN, José Gimeno. Consciência e acção sobre a prática como libertação profissional dos professores. In: NÓVOA, Antonio (Org.). Profissão professor. 2. ed. Porto: Porto Editora, 1999. p. 63-92.

TARDIF, Maurice. Saberes docentes e formação profissional. $4^{\mathrm{a}}$ Ed. Rio de Janeiro: Vozes, 2002.

ZABALZA, Miguel. $O$ ensino universitário: seu cenário e seus protagonistas. Trad. Ernani Rosa. Porto Alegre: Artmed, 2004. 